\title{
How should we respond to the highly toxogenic NAP1/ribotype 027 strain of Clostridium difficile?
}

\author{
Thomas J. Louie
}

$\infty$

See related articles pages I020 and I037.

I $\mathrm{t}$ is common knowledge across Canada and elsewhere that multiple hospitals in Quebec have experienced a disastrous and highly lethal outbreak of nosocomial Clostridium difficile-associated disease (CDAD) in the past 2 years. Unaffected regions may be indeed be thankful that they have not been confronted with this formidable foe. It has recently been determined that two-thirds of the nosocomial cases in the Sherbrooke region (and a similar proportion in other hospitals within Quebec) were the result of infection with one strain, a ribotype 27, North American pulso-type I (NAPI), toxinotype III organism that makes roughly I5-20 times the amount of toxin as "normal" strains. ${ }^{1}$ The organism has an altered repressor gene with an 18 base-pair nucleotide deletion. ${ }^{2}$ Fulminant disease poorly responsive to front-line metronidazole therapy and associated with a high risk of acute clinical deterioration necessitating intensive care and assessment for colectomy has been a common experience in the affected hospitals in Quebec. ${ }^{3}$

Obtaining a precise measurement of the lethality of this strain has been difficult. In this issue ${ }^{4}$ Jacques Pépin and associates report on a stringent case-control study that measured the risk of dying from this infection. Out of a database of 56I9 patients with 742I episodes of care for CDAD since I99I, the authors selected I6I patients (mean age 77 years) diagnosed with CDAD during 2003-2004 as new cases in the outbreak period. For each case, 5 controls were selected to match for age ( \pm 2 years), sex, underlying disease (Charlson Comorbidity Index score) and duration of hospital stay. The validity of the underlying disease score was confirmed with the whole cohort, demonstrating a step-wise increasing risk of death by age and by cumulative underlying disease burden, and a steep rise in risk of death in the elderly population. In the study population, it was concluded that death within 30 days was more than 3 times as likely if CDAD complicated the hospital stay: $23 \%$ (37/I6I) of patients with CDAD died, versus $7 \%(46 / 656)$ of controls. At 12 months, the cumulative attributable mortality was $16.7 \%$. In addition to excess deaths, prolonged hospital stays and a pattern of readmission after relapse and secondary complications were observed in those affected by $C$. difficile infection.

Infection with this lethal strain is not restricted to Quebec.
At least 6 US sites in diverse states were affected in 2002-2004, ${ }^{5}$ and in the past year highly lethal infection with this same organism or a closely related strain has appeared in several hospitals in the United Kingdom ${ }^{6}$ and the Netherlands. ${ }^{7}$ It is also unclear to what extent the organism has shown up in hospitals outside of Quebec. Results of a 6month survey of all nosocomial CDAD cases in 34 hospitals across Canada between November 2004 and May 2005 with strain typing of organisms by the National Laboratory in Winnipeg is awaited. However, this highly lethal strain does not represent the emergence of a novel pathogen. This strain, or a closely related one, was first identified in $1987^{8}$ and has been identified as a minor strain accounting for less than $5 \%$ of isolates on surveys, without apparent association with large outbreaks or increased lethality - at least until now. In addition to the production of large amounts of cytotoxin A and $\mathrm{B}$, this strain type possesses the ability to make an additional large clostridial toxin, termed "binary toxin." However, the contribution of this additional toxin to lethality is unclear, and most of the current evidence supports lethality by way of cytotoxin A and B. ${ }^{1}$

What factors account for the emergence of this strain, and what practical steps can be taken to control outbreaks? An elderly hospital population, crowded wards, suboptimal toilet-bed ratios and poor infection control performance are often cited as predisposing factors. However, these issues in health care delivery were present long before the Quebec outbreak, and the correction of physical plant deficiencies will not be achieved any time soon. That being said, we need to begin long-neglected upgrades in hospitals infrastructure, as there is a lag of almost a decade between the intention to build and the completion of projects. The argument to proceed in this direction is supported by the recent observation that the risk of nosocomial acquisition of methicillin-resistant Staphylococcus aureus, vancomycin-resistant enterococci and $C$. difficile was reduced 4 -fold after the medical teaching unit at the Foothills Medical Centre in Calgary moved from a 5:I to a I:I bed-toilet ratio. A major upgrade of infection-control resources is urgently needed to reinforce practice standards, in part to compensate for the transmission-prone hospital environment. This should include added medical support to complement the work of infection control practi- 
tioners in persuading front-line health care workers to pay more than lip service to infection control practices.

Another important avenue of control is antibiotic restriction leading to deselection of this lethal strain. Cephalosporins, being the most common inducers of CDAD, have little or no activity against the pathogen and can deleteriously affect normal gut flora, thereby selecting for the organism. Similarly, outbreaks of clindamycin-resistant $C$. difficile infection are explosively induced with the use of this agent ${ }^{9}$ and can be brought under control by restrictions on use..$^{10}$ In the past decade, quinolones have become the de facto replacement class for aminoglycosides in hospital medicine and also have become widely used in community practice. Whereas early in-vitro susceptibility studies of quinolones versus $C$. difficile strains showed MIC (minimum inhibitory concentration) values in the susceptible range, particularly for newer quinolones, the NAPr/ribotype 027 strain is highly resistant to older and new quinolones used in clinical practice. The acquisition of quinolone resistance by this strain could account for the outbreaks, and quinolones as a class have come under increasing scrutiny as potential inducers of CDAD. ${ }^{11}$ If earlier models of control apply, it would appear that major formulary controls should be imposed in affected hospitals. In addition to restrictions on the use of third-generation cephalosporins and clindamycin, consideration should be given to curbing the wholesale use of quinolones as primary therapy against Gram-negative pathogens. Short-term use of aminoglycosides, a monobactam and co-trimoxazole for susceptible organisms are viable alternatives. In the context of an actual outbreak, it would be difficult to propose a randomized study of exposure to quinolones.

Dial and colleagues ${ }^{12}$ also raised the issue of proton-pump inhibitors as a co-factor associated with a higher risk of CDAD. This could be another target for control, but it would be important to clarify the relative role of proton-pump inhibitors versus antibiotics. At present, from a historical perspective, antibiotic selection is more likely to be a primary driver of the outbreak. Therefore, our focus should should be on formulary containment complemented by vigorous infection-control efforts.
This article has been peer reviewed.

Dr. Louie is with the Infectious Diseases Division, Department of Medicine, University of Calgary, and is Medical Director, Infection Prevention \& Control, Calgary Health Region Hospitals, Calgary, Alta.

Competing interests: None declared.

\section{REFERENCES}

I. Warny M, Pépin J, Fang A, et al. Toxin production by an emerging strain of Clostridium difficile associated with outbreaks of severe disease in North America and Europe. Lancet 2005;366(949I):1079-84

2. Spigalia P, Mastrantonio P. Molecular analysis of the pathogenicity locus and polymorphism in the putative negative regulator of toxin production (TcdC) among Clostridium difficile clinical isolates. J Clin Microbiol 2002;40:3470-75.

3. Pépin J, Valiquette L, Alary ME, Villemure P, Pelletier A, Forget K, et al. Clostridium difficile-associated diarrhea in a region of Quebec from I99I t6 2003: a changing pattern of disease severity. CMAJ 2004;17I(5):466-72.

4. Pépin J, Valiquette L, Cossette B. Mortality attributable to nocosomial Clostridium difficile-associated disease during an epidemic caused by a hypervirulent strain in Quebec. CMAJ 2005; I73(9):1037-4I.

5. McDonald LC, Killgore GE, Thompson A, et al and the $C$. difficile investigation team. Emergence of an epidemic strain of Clostridium difficile in the United States 200I-4: potential role for virulence factors and antimicrobial resistance traits. Abstract LB-2, 42nd Annual Meeting of the Infectious Disease Society of America, Boston, October 2004

6. ProMED-mail. Clostridium difficile, increased virulence - UK (England) (05) ProMED-mail 2005 June 30: 20050630.1843. Available: www.promedmail.org (accessed 2005 Sept 25).

7. van Steenbergen J, Debast S, van Kregten E, van den Berg R, Notermans D, Kuijper E. Isolation of Clostridium difficile ribotype 027, toxinotype III in the Netherlands after increase in C. difficile-associated diarrhea. Eurosurveillance Wkly Release 2005; ro. Available: www.eurosurveillance.org/ew/2005/050714.asp (accessed 2005 Sept 25).

8. Popoff MR, Rubin EJ, Gill DM, Boquet P. Actin-specific ADP-ribosyltransferase produced by a Clostridium difficile strain. Infect Immun I988;56:2299-306.

9. Johnson S, Samore MH, Farrow KA, et al. Epidemics of diarrhea caused by a clindamycin-resistant strain of Clostridium difficile in four hospitals. $N$ Engl J Med I999;34I:I645-5I.

Io. Climo MW, Israel DS, Wong ES, Williams D, Coudron P, Markowitz SM. Hospitalwide restriction of clindamycin: effect on the incidence of Clostridium difficile-associated diarrhea and cost. Ann Intern Med 1998;128:989-95

II. Gerding DN. Clindamycin, cephalosporins, fluoroquinolones, and Clostridium difficile-associated diarrhea: this is an antimicrobial resistance problem. Clin Infect Dis 2004:38:646-8.

I2. Dial S, Alrasadi K, Manoukian C, Huang A, Menzies D. Risk of Clostridium difficile diarrhea among hospital inpatients prescribed proton pump inhibitors: cohort and case-control studies. $C M A J$ 2004;17I(I):33-8.

Correspondence to: Dr. Thomas J. Louie, $R m A G W_{5}$, Foothills Medical Centre, $1403-29$ St. NW, Calgary AB T2N 2 T9

\section{LEADERSHIP}

$C M A J$ is a founding member of the International Committee of Medical Journal Editors, an organization that is devoted to ensuring the highest integrity in scientific publishing and is a driving force in the mandatory registration of clinical trials. 